\title{
Pengaruh electronic word of mouth dan food quality terhadap keputusan pembelian
}

\author{
Sri Wiludjeng Sunu Purwaningdyah* \\ Universitas Widyatama \\ Jl. Cikutra 204A. Bandung. 40125. Indonesia \\ sri.wiludjeng@widyatama.ac.id \\ *Penulis Korespondensi
}

Submitted: Oct 16, 2018; Reviewed: Jan 30, 2019; Accepted: Apr 23, 2019

\begin{abstract}
The development of information technology nowadays impact on rapid economic growth. It makes entrepreneurs have to upgrade their businesses thus they can compete both nationally and internationally. This condition also encourages entrepreneurs both in the manufacturing sector and especially culinary services to be able to capture a wider market share. One marketing strategy that can be used to reach consumers more broadly is through electronic word of mouth (e-WOM), to convey or inform, offer, and remind about its products. No less important is the attention of culinary entrepreneurs to pay attention to the quality of their products (food quality). The aim of this study is to find out how e-WOM and food quality capabilities influence consumer purchasing decisions at Mie Merapi in Bandung. The research method used is descriptive and quantitative methods. While the sampling method with accidental random sampling technique. The analytical tool used is multiple regression. The results showed thate-WOM was able to positively influence consumer purchasing decisions but was not significant, because e-WOM conducted by Mie Merapi was less attractive, because culinary noodles were an ordinary culinary. Food quality able to provide a positive significant influence on consumer purchasing decisions at Mie Merapi in Bandung, because consumers are more convinced about the product needed is quality. This research suggests Mie Merapi to inform and offer products through consumers testimonials that have made direct purchases, because user reference is a valuable experience and as a consideration in purchasing products. In order for this user reference to be disseminated more widely, it can be used to invite meals directly to the place by giving gifts. For example, free noodle for first five customers.
\end{abstract}

Keywords: buying decision; e-WOM; food quality

Abstrak: Perkembangan teknologi infomasi saat ini berdampak pada pertumbuhan ekonomi yang sangat pesat. Hal ini ini menuntut para pengusaha untuk memutakhirkan usahanya agar mampu bersaing baik secara nasional maupun internasional. Kondisi ini pun mendorong para pengusaha baik dibidang manufaktur maupun jasa khususnya kuliner harus mampu merebut pangsa pasar yang lebih luas. Salah satu strategi pemasaran yang dapat digunakan untuk menjangkau konsumen lebih luas adalah melalui electronic word of mouth (e-WOM), untuk menyampaikan atau menginformasikan, menawarkan, serta mengingatkan tentang produknya. Tidak kalah penting perhatian para pengusaha kuliner juga untuk memperhatikan kualitas produknya (food quality). Penelitian ini bertujuan untuk mengetahui bagaimana kemampuan e-WOM dan food quality mempengaruhi keputusan pembelian konsumen pada Mie Merapi di Bandung. Metode penelitian yang digunakan adalah metode deskriptif dan kuantitatif. Sedangkan metode pengambilan sampel dengan teknik accidental random sampling. Alat analisis yang digunakan regresi berganda. Hasil penelitian 
menunjukkan bahwae-WOM mampu memengaruhi keputusan pembelian konsumen secara positif tetapi tidak signifikan. Hal ini disebabkan e-WOM yang dilakukan oleh Mie Merapi kurang menarik, karena kuliner mie merupakan kuliner yang biasa saja. Food quality mampu memberikan pengaruh positif signifikan terhadap keputusan pembelian konsumen pada Mie Merapi di Bandung, karena konsumen lebih meyakini tentang produk yang dibutuhkan adalah berkualitas. Penelitian ini menyarankanMie Merapi dapat menginformasikan dan menawarkan produk dapat melalui kesaksian konsumen yang telah melakukan pembelian secara langsung, karena referensi pengguna adalah pengalaman yang berharga dan sebagai bahan pertimbangan dalam pembelian produk. Agar referensi pengguna ini dapat disebarkan lebih luas lagi, Mie Merapi dapat menggunakan cara mengundang makan langsung pada tempatnya dengan memberikan hadiah. Misalnya lima pembeli pertama mendapatkan mie gratis.

Kata-kata Kunci: e-WOM; food quality; keputusan pembelian

\section{PENDAHULUAN}

Perkembangan teknologi informasi yang pesat membuat gaya hidup manusia semakin mudah, terutama sejak hadirnya Internet. Dengan adanya Internet, segala kebutuhan manusia akan lebih mudah terpenuhi, karena hal ini mampu memudahkan mendapatkan berbagai informasi. Orang-orang mampu berkomunikasi dengan keluarga, teman ataupun rekan bisnis dimanapun berada. Indonesia sendiri merupakan salah satu negara pengguna Internet terbesar (Kementerian Komunikasi dan Informatika Republik Indonesia, 2018). Jumlah penduduk Indonesia mencapai 255,2 juta jiwa, dan tercatat 72,7 juta jiwa sebagai pengguna aktif Internet. Jumlah tersebut tercatat sebagai pengguna media sosial (Kompas, 2018). Sedangkan tahun 2016, pengguna Internet tercatat 132,7 juta manusia dan tahun 2017 tercatat 143 juta manusia dengan jumlah penduduk 262 juta jiwa (Kementerian Komunikasi dan Informatika Republik Indonesia, 2018). Kondisi peningkatan pengguna Internet ini menunjukkan, betapa perlu dan pentingnya teknologi informasi melalui Internet. Hal ini menunjukkan bahwa Internet mampu mengubah cara manusia ataupun konsumen berkomunikasi, berpendapat dalam bidang bisnis maupun non bisnis.

Mahendrayasa, Kumadji, \& Abdillah (2014) menjelaskan bahwa word of mouth (WOM) pada dasarnya adalah pesan tentang produk atau jasa suatu perusahaan, ataupun tentang perusahaan itu sendiri, dalam bentuk komentar tentang kinerja produk, keramahan, kejujuran, kecepatan pelayanan dan hal lainnya yang dirasakan dan dialami oleh seseorang yang disampaikan kepada orang lain. Chan \& Ngai (2011) menjelaskan bahwaelectronic word of mouth (e-WOM) dapat meningkatkan efektivitas pemasaran, dan juga mampu menghancurkan brand image perusahaan, saat terjadi ketidaksesuaian antara keinginan konsumen dengan kenyataan yang diterimanya. Lebih lanjut Jalilvand \& Samiei (2012) mengatakan $e-W O M$ sebagai "Pernyataan negatif atau positif yang dibuat oleh konsumen aktual, potensial atau konsumen sebelumnya mengenai produk atau perusahaan dimana informasi ini tersedia bagi orang-orang ataupun institusi melalui media Internet”. Melalui kegiatan seperti inilah konsumen dapat mengetahui kualitas dari suatu produk atau jasa.

Kondisi tersebut memungkinkan terjadinya persaingan yang ketat di antara produsen atau penyedia jasa, termasuk produsen atau jasa kuliner, khususnya restoran Mie Merapi di Bandung. Hal ini terjadi, karena restoran "Mie Merapi" berusaha memuaskan konsumennya, dan tentunya akan berdampak pada peningkatan penjualan. Peningkatan penjualan ini salah satunya dapat dilakukan dengan jalan promosi. Hermawan (2013, p. 238) menjabarkan pengertian promosi sebagai salah satu prioritas dari kegitan pemasaran yang diberitahukan kepada konsumen bahwa perusahaan meluncurkan produk baru yang menggoda konsumen untuk melakukan kegiatan pembelian. Sedangkan Kotler \& Armstrong (2012) mengemukakan promosimerupakan kegiatan yang mengkomunikasikan manfaat dari sebuah produk dan membujuk target konsumen untuk membeli produk tersebut. Salah satu alat promosi yang paling efektif saat ini adalah $e$-WOM marketing. Hal ini terjadi karena fakta bahwa $e$-WOM sekarang merupakan faktor yang paling dominan yang mempengaruhi keputusan pembelian (Baitaineh, 2015).

Pemahaman $e$-WOM dibidang bisnis sangat penting, khususnya $e$-WOM dengan jejaring sosial, karena media ini mampu menjangkau khalayak global dengan cepat dan mudah (Daugherty \& Hoffman, 2014). Persaingan ini tentunya akan mempengaruhi keputusan beli konsumen, karena 
konsumen lebih banyak mendapatkan informasi-informasi yang sesuai mereka butuhkan, sehingga akan berpengaruh pada keputusan beli konsumen. Tentunya konsumen akan melakukan pembelian produk yang sesuai kebutuhan mereka. Hal ini akan memungkinkan berdampak pada perubahan pendapatan penjual atau perusahaan yang dalam hal ini adalah Restoran Mie Merapi Bandung.

Sesuai dengan wawancara yang dilakukan dengan pemilik Mie Merapi, pada periode bulan Agustus 2017, periode tahun 2016 Mie Merapi mengalami penurunan sebesar 5 persen sampai dengan 30 persendari periode sebelumnya padahal dalam memasarkan produknya Mie Merapi juga menggunakan jejaring sosial atau media sosial (Facebook, Twitter, Instagram dan lainnya), selain menggunakan media non-electronic. Penggunaan media sosial yang dilakukakan oleh Mie Merapi belum mampu mendongkrak penjualan yang lebih tinggi. Sedangkan penelitian dari Ekawati (2014) menyatakan bahwa terdapat pengaruh langsung secara positif dan signifikan terhadap keputusan pembelian WRP diet, artinya apabila $e$-WOM berubah positif akan menaikkan keputusan pembelian. Sehingga penjualan akan mengalami kenaikkan. Hal ini sangat diperlukan peranan media sosial atau jaringan sosial.

Media sosial dalam kegiatan bisnis mempunyai peran yang sangat penting, hal ini dikarenakan keberlangsungan dari bisnis tergantung media yang akan digunakan. Carr \& Hayes (2015) menjelaskan bahwa media sosial adalah media yang berbasis Internet yang memungkinkan pengguna memiliki kesempatan untuk berinteraksi dan mempresentasikan diri, baik secara seketika ataupun tertunda, dengan khalayak luas. Sedangkan jaringan sosial merupakan hubungan yang tercipta antar individu, kelompok, ataupun organisasi secara formal ataupun informal. Sehingga dapat dijelaskan hubungan sosial adalah gambaran dari kerjasama yang didasari oleh ikatan sosial yangaktif. Hubungan sosial ini akan mempunyai jangkauan yang lebih luas dan secara global, karena didukung oleh media sosial. Kondisi inilah yang dimanfaatkan oleh bidang bisnis dalam rangka mempromosikan barang dan jasanya secara global.

\section{E-WOM}

E-WOM merupakan salah satu alat promosi yang effektif, karena $e$-WOM menginformasikan pengalaman-pengalaman individu atau suatu kelompok secara jelas. Lebih lanjut Jansen et al. (2009) mengatakan bahwa secara garis besar, $e$-WOM mampu memberikan alternatif informasi baru secara anonim dan rahasia serta mampu memberikan informasi melintasi batasan jarak dan wilayah.

Umumnya, proses komunikasi antarmanusia dilakukan dengan komunikasi dari mulut ke mulut atau yang lazim disebut dengan WOM dan bila hal tersebut dilakukan dengan media elektronik, maka disebut $e$-WOM. Menurut Goyette et al.(2010), untuk mengevaluasi $e$-WOM dapat dilakukan melalui tiga indikator yaitu intensity, positive valence, dan content. Hal ini di dukung hasil penelitian dari Hasan \& Setyaningtyas(2015) yang menyatakan bahwa $e$-WOM dalam hal ini faktor-faktor $e$-WOM berpengaruh positif terhadap keputusan berkunjung wisatawan ke Desa Wisata Nglanggeran Gunung Kidul.

Penelitian lain dari Ekawati (2014) menyatakan bahwa $e$-WOM berpengaruh langsung terhadap keputusan pembelian WRP dari Nutrifood. Hal ini jelas menunjukkan bahwa, apabila $e$-WOM dari suatu produk atau perusahaan baik maka dapat meningkatkan keputusan pembelian konsumen. Khususnya produk kuliner yang mempunyai kualitas bagus atau sesuai dengan keinginan konsumen, maka konsumen tidak segan-segan menyampaikan hal ini kepada konsumen yang lainnya.

\section{Food quality}

Definisi food quality dari setiap peneliti memiliki pengertian dan kriteria yang berbeda-beda. Hal ini disebabkan adanya kondisi yang dinamis yang berhubungan dengan produk, manusia, proses dan lingkungan. Namun kualitas merupakan kebutuhan dari setiap individu atausetiap orang dalam melakukan keputusan belinya. Kualitas ini tidak saja berlaku pada barang tetapi juga berlaku pada produk makanan atau kuliner. Individu atau manusia yang melakukan keputusan beli tentu ingin makan yang berkualitas pula, yang memenuhi selera mereka. Amanah (2010) menyatakan bahwa food quality diukur berdasarkan nilai nutrisinya, tingkat bahan yang digunakan, rasa, dan penampilan dari produk. Kualitas makanan akan berpengaruh pada kepuasan konsumen untuk itu restorant atau penjual makanan diharapkan kualitas makanan menjadi strategi pemasarannya. 
Keputusan pembelian

Setiyadi (2010) menyampaikan keputusan pembelian adalah perilaku membeli yang mengandung makna kegiatan individu secara langsung terlibat dalam pertukaran uang dengan produk (barang dan jasa). Pengambilan keputusan untuk membeli suatu produk tertentu akan melibatkan kegiatan fisik, diantaranya adalah pengenalan masalah, pencarian informasi, evaluasi, seleksi alternatif produk dan pelaksanaan pembelian. Seperti halnya penelitian Syafaruddin et al. (2016) menyatakan bahwa $e$ WOM berpengaruh positif dan signifikan terhadap keputusan pembelian pada online shopping zafertech.com.

Fenomena di atas mendorong penulis untuk melakukan penelitian lebih lanjut dengan tujuan bagaimana tanggapan responden tentang $e$-WOM dan food quality yang dilakukan oleh restoran Mie Merapi serta seberapa besar $e-W O M$ dan food quality mampu mempengaruhi keputusan pembelian konsumen.

Kerangka pemikiran

$E$-WOM memberikan informasi yang dapat mempengaruhi keputusan pembelian, hal ini disebabkan konsumen lebih mempercayai opini rekan atau teman dan bahkan orang lain melalui jejaring sosial dibandingkan mendapat informasi langsung dari perusahaan.Machfoedz (2013) mengemukakan bahwa keputusan pembelian adalah suatu proses penilaian dan pemilihan dari berbagai alternatif sesuai dengan kepentingan-kepentingan tertentu dengan menetapkan suatu pilihan yang dianggap paling menguntungkan.

Terdapat beberapa faktor yang mempengaruhi pengambilan keputusan pembelian suatu produk, diantaranya $e$-WOM dan food quality, yang menjadi objek penelitian ini adalah Restorant Mie Merapi yang dapat digambarkan pada Gambar 1 sebagai berikut.

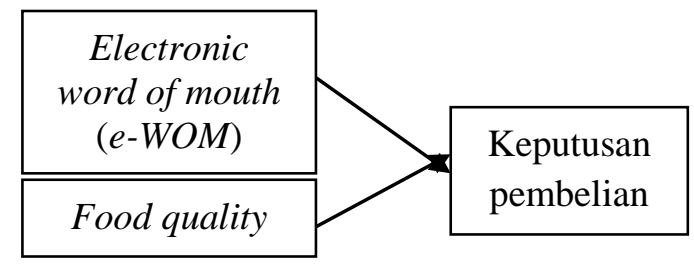

Gambar 1. Kerangka Pemikiran

Hipotesis penelitian

Merujuk pada kerangka pemikiran di atas, dapat dihipotesiskan bahwa e-WOM dan food quality berpengaruh positif terhadap pembelian pada Restoran Mie Merapi di Bandung.

\section{METODE}

Metode yang digunakan dalam penelitian ini yaitu bersifat deskriptif dan kuantitatif. Metode penelitian deskrpitif adalah "penelitian yang dilakukan untuk mengetahui keberadaan variabel mandiri, baik hanya pada satu variabel atau lebih (variabel yang berdiri sendiri atau variabel bebas) tanpa membuat perbandingan variabel itu sendiri dan mencari hubungan dengan variabel lain" (Sugiyono, 2017). Sedangkan penelitian kuantitatif diartikan sebagai metode penelitian yang berlandaskan pada filsafat positivisme, digunakan untuk meneliti pada populasi atau sampel tertentu, pengumpulan data menggunakan instrumen penelitian, analisis data yang bersifat kuantitatif atau statistik, dengan tujuan untuk menguji hipotesis yang telah ditetapkan (Sugiyono, 2017).

Adapun data dalam penelitian ini adalah data primer dan data sekunder. Menurut Sugiyono (2017), data primer adalah data yang diperoleh langsung dari sumber pertama yaitu dari responden. Sedangkan data sekunder adalah data primer yang telah diolah lebih lanjut oleh pihaklain yang dapat berupa catatan, tabel, diagram dan grafik yang menjelaskan suatu permasalahan yang terkait dengan masalah yang diteliti. Data tersebut diatas dapat diperoleh dengan cara observasi, wawancara, dan penyebaran kuesioner. 
Populasi

Populasi dalam penelitian ini adalah konsumen Mie Merapi di Bandung. Pengumpulan data dilakukan dengan cara observasi, wawancara, dan penyebaran kuesoiner. Sedangkan teknik sampling yang digunakan adalah accidental atau convinience sampling. Teknik accidental sampling yaitu pengambilan sampel secara aksidental dengan mengambil kasus atau responden yang kebetulan ada atau tersedia di suatu tempat sesuai dengan konteks penelitian (Notoatmodjo, 2010). Adapun jumlah responden atau sampel dalam penelitian ini berjumlah 100 orang (Riduwan, 2013) yang dapat diperoleh dengan rumus sebagai berikut.

$n=0,25\left(\frac{Z \alpha / 2}{e}\right)^{2}=0,25\left(\frac{1,96}{0,1}\right)^{2}=96,04$ (dibulatkan menjadi 100)

Keterangan:

$\mathrm{n} \quad=$ jumlah sampel

$\mathrm{Z} \alpha / 2=$ nilai yang diperoleh dari tabel normal atas tingkat keyakinan

$\mathrm{e} \quad=$ tingkat kesalahan dalam penarikan sampel.

Definisi operasional variabel

Tabel 1.Operasional Variable Penelitian

\begin{tabular}{|c|c|c|c|}
\hline $\begin{array}{c}\text { Variabel } \\
\text { dan Konsep Variabel }\end{array}$ & Dimensi & Indikator & $\begin{array}{c}\text { Skala } \\
\text { Pengukuran }\end{array}$ \\
\hline \multirow{7}{*}{$\begin{array}{l}e \text {-WOM adalah sebuah media } \\
\text { komunikasi untuk saling berbagi } \\
\text { infor-masi mengenai suatu produk } \\
\text { atau jasa yang telah dikonsumsi antar } \\
\text { konsumen yang tidak saling } \\
\text { mengenal dan bertemu sebelumnya } \\
\text { (Gruen, Osmonvekov, dan } \\
\text { Czaplewski, 2006; Goyette, Ricard, } \\
\text { Bergeron, \& Marticotte, 2010) }\end{array}$} & Intensity & $\begin{array}{l}\text { Frekuensi analisis } \\
\text { informasi }\end{array}$ & Ordinal \\
\hline & & Frekuensi interaksi & Ordinal \\
\hline & $\begin{array}{l}\text { Valence of } \\
\text { opinion }\end{array}$ & Banyaknya ulasan & Ordinal \\
\hline & & Komentar positif & Ordinal \\
\hline & & Komentar negatif & Ordinal \\
\hline & Content & $\begin{array}{l}\text { Informasi variasi } \\
\text { produk }\end{array}$ & Ordinal \\
\hline & & $\begin{array}{l}\text { Informasi tentang } \\
\text { harga }\end{array}$ & Ordinal \\
\hline \multirow{8}{*}{$\begin{array}{l}\text { Food quality adalah karakteristik } \\
\text { dari suatu makananyang dapat } \\
\text { diterima oleh konsumen (Potter \& } \\
\text { Hotchkiss, 1995). }\end{array}$} & Nilai nutrisi & Kandungan gizi & Ordinal \\
\hline & Bentuk & Penampilan makanan & Ordinal \\
\hline & Warna & Warna & Ordinal \\
\hline & Konsisten & Produknya standar & Ordinal \\
\hline & $\begin{array}{l}\text { Tingkat olahan } \\
\text { yang digunakan }\end{array}$ & $\begin{array}{l}\text { Kualitas bahan yang } \\
\text { digunakan }\end{array}$ & Ordinal \\
\hline & Rasa & & \\
\hline & & Rasa Enak & Ordinal \\
\hline & $\begin{array}{l}\text { Penampilan } \\
\text { Produk }\end{array}$ & Penampilan produk & Ordinal \\
\hline $\begin{array}{l}\text { Keputusan beli adalah proses } \\
\text { pengambilan keputusan untuk }\end{array}$ & $\begin{array}{l}\text { Pengenalan } \\
\text { masalah }\end{array}$ & Adanya masalah & Ordinal \\
\hline
\end{tabular}




$\begin{array}{llll}\begin{array}{l}\text { membeli suatu produk (Munandar, } \\ \text { 2011) }\end{array} & \begin{array}{l}\text { Pencarian } \\ \text { informasi }\end{array} & \begin{array}{l}\text { Pencarian referensi } \\ \text { makanan }\end{array} & \text { Ordinal } \\ & \text { Evaluasi } & \begin{array}{l}\text { Memilih makanan } \\ \text { yang cocok }\end{array} & \text { Ordinal } \\ & \begin{array}{l}\text { Seleksi alternatif } \\ \text { produk }\end{array} & \begin{array}{l}\text { Menentukan pilihan } \\ \text { makanan }\end{array} & \text { Ordinal } \\ & \begin{array}{l}\text { Pelaksanan } \\ \text { pembelian }\end{array} & \begin{array}{l}\text { Melakukan } \\ \text { pembelian }\end{array} & \text { Ordinal }\end{array}$

Analisis data

Analisis regresi berganda dilakukan untuk menjelaskan kontribusi atau pengaruh masing-masing variabel independen $\left(\mathrm{X}_{1} ; \mathrm{X}_{2}\right)$ terhadap variabel dependen atau terikat $(\mathrm{Y})$ dengan rumusan sebagai berikut.

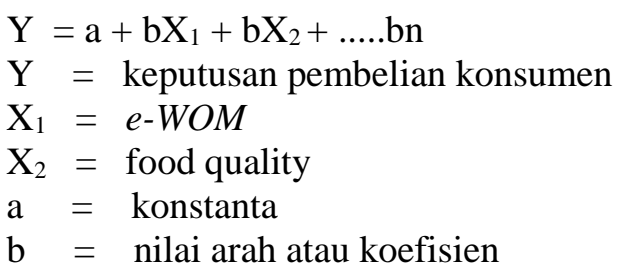

\section{HASIL DAN PEMBAHASAN}

Hasil analisa regresi menunjukkan $\mathrm{Y}=17,356+0,027 \mathrm{X}_{1}+0,629 \mathrm{X}_{2}$. Hal ini dapat dijelaskan bahwa e-WOM $\left(\mathrm{X}_{1}\right)$ secara positif mampu memberikan pengaruh terhadap keputusan beli konsumen, yaitu sebesar 0,027 atau sebesar 2,7 persen. Hal ini dapat dikatakan mampu mempengaruhi karena $t$ tabel lebih besar daripada t hitung yaitu sebesar 1,965 lebih besar daripada 0,432 , namun pengaruhnya tidak signifikan $(0,05<0,666)$. Pengaruh yang tidak signifikan ini dapat dijelaskan bahwa Mie Merapi dalam mempromosikan produknya kurang menarik, alat promosi atau media sosial yang digunakan kurang tepat dan waktu penyampaikan atau informasi produk yang kurang tepat. Namun untuk food quality $\left(\mathrm{X}_{2}\right)$ mampu mempengaruhi secara positif dan signifikan sebesar 0,629 yaitu sebesar 62,9 persen dan signifikan karena 0,05 lebih besar daripada 0,000 .

Pengaruh food quality ini lebih besar daripada pengaruh $e$-WOM terhadap keputusan beli konsumen pada Mie Merapi di Bandung dibandingkan variabel $e$-WOM, yaitu sebesar 0,629 lebih besar daripada 2,027. Hal ini menunjukkan bahwa kualitas produk merupakan pilihan utama konsumen Mie Merapi. Misalnya melalui penyajian, tekstur, rasa, aroma, ukuran atau volume, bentuk, warna, konsistensi. Makanan dalam hal ini Mie Merapi yang lezat dan segar mampu memainkan peran penting dalam upaya mengungguli pesaing. Hasil pengolahan data dipaparkan pada Tabel 2 berikut.

Tabel 2. Pengaruh Variabel Independen terhadap Variabel Dependen

\begin{tabular}{|c|c|c|c|c|c|}
\hline \multirow{2}{*}{ Model } & \multicolumn{3}{|c|}{$\begin{array}{c}\text { Unstandardized Standardized } \\
\text { Coefficients Coefficients }\end{array}$} & \multirow{2}{*}{$t$} & \multirow{2}{*}{ Sig. } \\
\hline & $B$ & $\begin{array}{l}\text { Std. } \\
\text { Error }\end{array}$ & Beta & & \\
\hline 1 (Constant) & 17.356 & 2.062 & & 8.419 & .000 \\
\hline$e-W O M$ & .027 & .063 & .036 & .432 & .666 \\
\hline Food quality & .629 & .084 & .618 & 7.487 & .000 \\
\hline
\end{tabular}

a. Dependent Variable: Keputusan Beli 


\section{SIMPULAN DAN SARAN}

Berdasarkan pembahasan di atas, maka penulis dapat menyimpulkan bahwa $e$-WOM ternyata mampu mempengaruhi keputusan beli konsumen. Begitu pula food quality mampu mempengaruhi keputusan beli konsumen secara positif dan signifikan. Namun $e$-WOM mampu mempengaruhi lebih kecil dibanding dengan food quality. Hal ini disebabkan karena $e$-WOM kurang menjadi perhatian konsumen dalam melakukan pembelian. Konsumen lebih memperhatikan pada kualitas makanannya. Oleh karena itu, Mie Merapi disarankan memperhatikan kualitas produknya, misalnya kualitas bahan baku, cara atau trik pengolahan yang benar, desain penyajian yang menarik dan yang paling penting rasa yang dapat memenuhi selera konsumen. Sehingga secara keseluruhan simpulan penelitian ini dapat dikatakan bahwa tanggapan konsumen terhadap e-WOM dan food quality dikatakan sudah baik.

\section{ACKNOWLEDGEMENTS}

Peneliti secara khusus menyampaikan ucapan terimakasih yang sebesar-besarnya kepada semua pihak yang telah membantu dan mendukung penulis dari penelitian hingga penulisan laporan dan publikasi. Tak lupa pula penulis sampaikan ucapan terimakasih kepada reviewer atas koreksinya demi sempurnanya makalah ini, sehingga layak untuk diterbitkan.

\section{REFERENSI}

Amanah, D. (2010). Pengaruh harga dan kualitas produk terhadap kepuasan konsumen pada Majestyk Bakery dan Cake Shop Cabang HM Yamin Medan. Jurnal Keuangan dan Bisnis, 71-87. doi:10.17605/OSF.IO/HNGVJ

Baitaineh, A. Q. (2015). The impact of perceived e-WOM on purchase intention: the mediating role of corporate image. International Journal of Marketing Studies, 7(1), 126-137. doi:10.5539/ijms.v7n1p126

Carr, C. T., \& Hayes, R. A. (2015). Social media: defining, developing, and divining. Atlantic Journal of Comunication, 23(1), 46-65. doi:10.1080/15456870.2015.972282

Chan, Y. Y. \& Ngai, E. W. (2011). Conceptualising electronic word of mouth activitity: an inputprocess-output perspective. Marketing Intelligence and Planning, 29(5), 488-516. doi:10.1108/02634501111153692

Daugherty, T. \& Hoffman, E. (2014). eWOM and the importance of capturing consumer attention within social media. Journal Marketing of Comunication, 82-102.

Ekawati, M. (2014). Pengaruh electronic word of mouth terhadap pengetahuan konsumen serta dampaknya pada keputusan pembelian: survei pada follower account twitter @WRPdiet. Jurnal Administrasi Bisnis, 14(2), 1-8.

Goyette, I., Ricard, L., Bergeron, J., \& Marticotte, F. (2010). e-WOM scale: word-of-mouth measurement scale for e-services context. Canadian Journal of Administrative Sciences, 27(1), 523. doi:10.1002/CJAS.129

Gruen, T., Osmonbekov, T., \& Czaplewski, A. (2006). e-WOM: the impact of customer-to-customer online know-how exchange on customer value and loyalty. Journal of Business Research, 59(4), 449-456. Retrieved from https://ideas.repec.org/a/eee/jbrese/v59y2006i4p449-456.html

Hasan, A. \& Setyaningtyas, N. W. (2015). Pengaruh electronic word of mouth pada media sosial Facebook terhadap keputusan berkunjung ke Desa Wisata Nglanggeran Gunungkidul. Jurnal Media Wisata, 13(1), 224-238.

Hermawan, A. (2013). Komunikasi Pemasaran. Jakarta: Erlangga.

Jalilvand, M. R., \& Samiei, N. (2012). The effect of electronic word of mouth on board image and purchase intention: an empirical study in the automobile industry in Iran. Marketing Intellegence \& Planning, 30(4), 460-476. doi:10.1108/02634501211231946

Jansen, B. J., Zhang, M., Sobel, K., \& Chowdury, A. (2009). Twitter power: tweets as electronic word of mouth. Journal of the American Society for Information Science and Technology, 60(11), 21692188. doi:10.1002/asi.21149 
Kementerian Komunikasi dan Informatika Republik Indonesia. (2018, 2 19). Retrieved from Jumlah Pengguna Internet 2017 Meningkat, Kominfo Terus Lakukan Percepatan Pembangunan Broadband: https://www.kominfo.go.id/content/detail/12640/siaran-pers-no-53hmkominfo022018tentang-jumlah-pengguna-internet-2017-meningkat-kominfo-terus-lakukan-percepatanpembangunan-broadband/0/siaran_pers

Kompas. (2018, 2 22). Bohang, Fatimah Kartini. (R. Wahyudi, Editor) Retrieved from Berapa Jumlah Pengguna Internet Indonesia?: https://tekno.kompas.com/read/2018/02/22/16453177/berapajumlah-pengguna-internet-indonesia?page $=$ all

Kotler, P. \& Amstrong, G. (2012). Prinsip-prinsip Pemasaran (Vol. Terjemahan). Jakarta: Erlangga.

Machfoedz, M. (2013). Pengantar Pemasaran Modern. Yogyakarta: Akademi Manajemen Pemasaran YPKPN.

Mahendrayasa, A. C., Kumadji, S., \& Abdillah, Y. (2014). Pengaruh word of mouth terhadap minat beli serta dampaknya pada keputusan pembelian: survei pada mahasiswa pengguna kartu selular GSM "IM3" angkatan 2011/2012 dan 2012/2013 Fakultas Ilmu Administrasi Universitas Brawijaya Malang. Jurnal Administrasi Bisnis, 12(1), 1-7. Retrieved from www.administrasibisnis.studentjournal.ub.ac.id

Munandar, A. S. (2011). Psikologi Industri dan Organisasi. Jakarta: Universitas Indonesia.

Notoatmodjo, S. (2010). Metodologi Penelitian Kesehatan. Jakarta: Rineka Cipta.

Potter, N. N., \& Hotchkiss, J. H. (1995). Food Science (Vol. 5). New York: Champman \& Hall.

Riduwan, A. (2013). Rumus dan Data dalam Analisis Statistika. Bandung: Alphabeta.

Setiyadi, N. J. (2010). Perilaku Konsumen. Jakarta: Kencana Prenada Media.

Sugiyono. (2017). Metode Penelitian Pendidikan Pendekatan Kuantitatif. Bandung: Alfabeta.

Syafaruddin, Suharyono, \& Kumadji, S. (2016). Pengaruh komunikasi e-wom terhadap kepercayaan (trust) dan niat beli serta dampaknya pada keputusan pembelian. Jurnal Bisnis dan Manajemen, $3(1), 65-72$. 